Military Technical College

Kobry El-Kobbah,

Cairo, Egypt

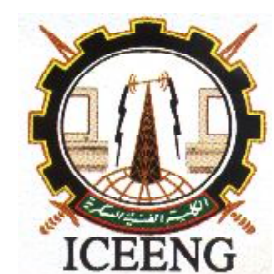

$9^{\text {th }}$ International Conference

on Electrical Engineering

ICEENG 2014

\title{
Design of Fuzzy PID Load Frequency Controller Tuned by Relative Rate Observer for the Egyptian Power System
}

\author{
By
}

M. A. Abdel Ghany*, M. E. Bahgat*, W. M. Refaey* and F. N. Hassan*

\section{$\underline{\text { Abstract: }}$}

This paper deals with the design of Fuzzy Proportional Integral and Derivative FPID controller self tuned by Relative Rate Observer RRO method. The developed approach is applied to the Load-Frequency Control LFC of the Egyptian power system EPS as a single area with multi unit power system. The studied power system comprises three power plants; non-reheat, reheat and hydro generation plants. The proposed FPID controller is designed on an average point of four loading conditions of the EPS during summer and winter of 2008. The effectiveness of the proposed FPID self tuned by RRO (FPID-RRO) has been demonstrated by introducing the system nonlinearities using MATLAB-SIMULINK simulation program. Moreover, a comparison of the FPID with FPID-RRO controllers under different disturbances and parameter variations are presented to validate the FPID-RRO controller. The simulation results reflect and prove fast settling time and accurate tracking for the LFC of the Egyptian Power System.

\section{Keywords:}

Egyptian power system load frequency control, Fuzzy Proportional Integral and Derivative, Self tuned Relative Rate Observer.

* Electrical Power \& Machines Department, Faculty of Engineering - Helwan, University of Helwan, Cairo, Egypt. 


\section{Introduction:}

Real-world load-frequency control systems usually use the proportional-integral and derivative PID type controllers [1-4]. Since the parameters of the PID controller are commonly tuned based on classical, experiences and trial-and-error approaches, they are incapable of obtaining good dynamical performance for a wide range of operating conditions and various load scenarios. For instance a classical PID controller gains remain constant for all values of input, however, a fuzzy controller gains depend on the range where the control variables exist at any instant. Since fuzzy controllers are nonlinear, it is more difficult to set the controller gains compared to PID controllers. The piece wise linearity of the fuzzy controller provides better system and improved robustness to changes in the system parameters as compared to a classical controller. Fuzzy logic is extensively used in processes where system dynamics are either very complex or exhibit a nonlinear character. The first fuzzy logic control FLC algorithm implemented by Mamdani [5-7] was constructed to synthesize the linguistic control protocol of a skilled human operator. Although, this type of FLC application was successful compared to classical controllers, the design procedure is dependent on the experience and knowledge of the operator and it is limited by the elucidation of the heuristic rules of control. Another benefit can easily add that any of needed nonlinearity can be performed by simply making specific changes in only some rules. So, the needed nonlinear control surface instead of the linear surface can be obtained.

In literature, various structures for FPID (including FPI and FPD) controllers have been proposed. Fuzzy PI control is known to be more practical than fuzzy PD because it is difficult for the fuzzy PD to remove steady state error. The fuzzy PI control, however, is known to give poor performance in transient response for higher order processes due to the internal integration operation. Thus, in practice the FPID controllers are more useful. To obtain proportional, integral and derivative control action all together, it is intuitive and convenient to combine FPI and FPD actions together to form a FPID controller [812]. The idea is to start with conventional PID controller, replace it with an equivalent linear fuzzy controller. This is relevant whenever a PID controller is possible or already implemented. Such a FPID controller is used in this study.

The values in terms of fuzzy logic gains (normalizing gains) are calculated with respect to the PID gains and usually determined during off-line design. The tuning of these gains can be performed during on-line adjustments to enhance the process performance, as well as to accommodate the adaptive capability to system uncertainty and process disturbance. Relative Rate Observer Self-tuning RROST method [13] is used for tuning gains includes I/O scaling factors SF and parameters of membership functions MF. The RRO idea is given in [13]. This method adjusts the scaling factors that correspond to the derivative and integral coefficient gains of the FPID controller using a fuzzy inference 
mechanism in an on-line manner.

In recent years, intelligent techniques based on artificial neural networks, fuzzy logic, multi-agent systems, genetic algorithm, simulated annealing, particle swarm optimization, ant colony optimization and hybrid intelligent techniques have been applied to power system operational and control problems which were not countered effectively by conventional and modern control techniques [14-18]. Also, the description of the process in terms of IF-THEN rules can be combined with a mathematical description of nonlinear plants in the form of a fuzzy system model (Takagi-Sugeno fuzzy) [19]. These techniques have been found very effective and reliable even to deal with design, implementation, synthesis and analysis of LFC schemes in complex and large order power systems.

This paper provides a simple and straightforward procedure for designing FPID-RRO for Egyptian power system EPS. The main contributions of this paper are given in two steps:

- The first step in the design procedure is to replace a conventional PID controller by a linear fuzzy controller acting like it. The closed loop system should thus show exactly the disturbances response. This is a check that the implementation is correct.

The FPID controller should be characterized by:

1. The control loop must have a sufficient degree of stability.

2. Following a step load change, the static error in frequency should be zero.

3. The frequency error should be minimized.

- The second step is eventually fine-tuning the linear FPID. The Relative Rate Observer RRO method is achieved as a tuning method. The proposed controllers are applied to the LFC of EPS as a single area with multi unit power system. Simulation is done when the controlled system is subjected to a severe disturbance with the presence of the inherent nonlinearity and system parameter changes. The results of the implementation for FPID have been compared with FPID-RRO.

\section{The Egyptian Load Frequency Control System}

The total installed generation capacity and peak load of the EPS in 2008 are approximately $22500 \mathrm{MW}$ and $19740 \mathrm{MW}$, respectively [20-23]. The EPS incorporates about 180 generating units belonging to the following categories:

1- Non-reheat generating units denoting the gas turbine power stations and a few of steam power stations and representing approximately $24 \%$ of the installed capacity.

2- Reheat generating units denoting the majority of thermal stations and combined cycle power station and representing approximately $62 \%$ of the installed capacity.

3 - Hydro electric power stations represent approximately $14 \%$ of the installed capacity. 
The national energy control center NECC of the Egyptian Electricity Authority has developed a dynamic power frequency model for the EPS [20-23]. The NECC model is originally built for solving load shedding problems and considers only the effect of primary reserve. The EPS consists of seven strongly tied zones. These zones have not considering any interconnection details and the study is carried out based on a single area power system model [20-23]. The validity of the model has been tested through two different generator outage contingencies in two different loading conditions [2023].

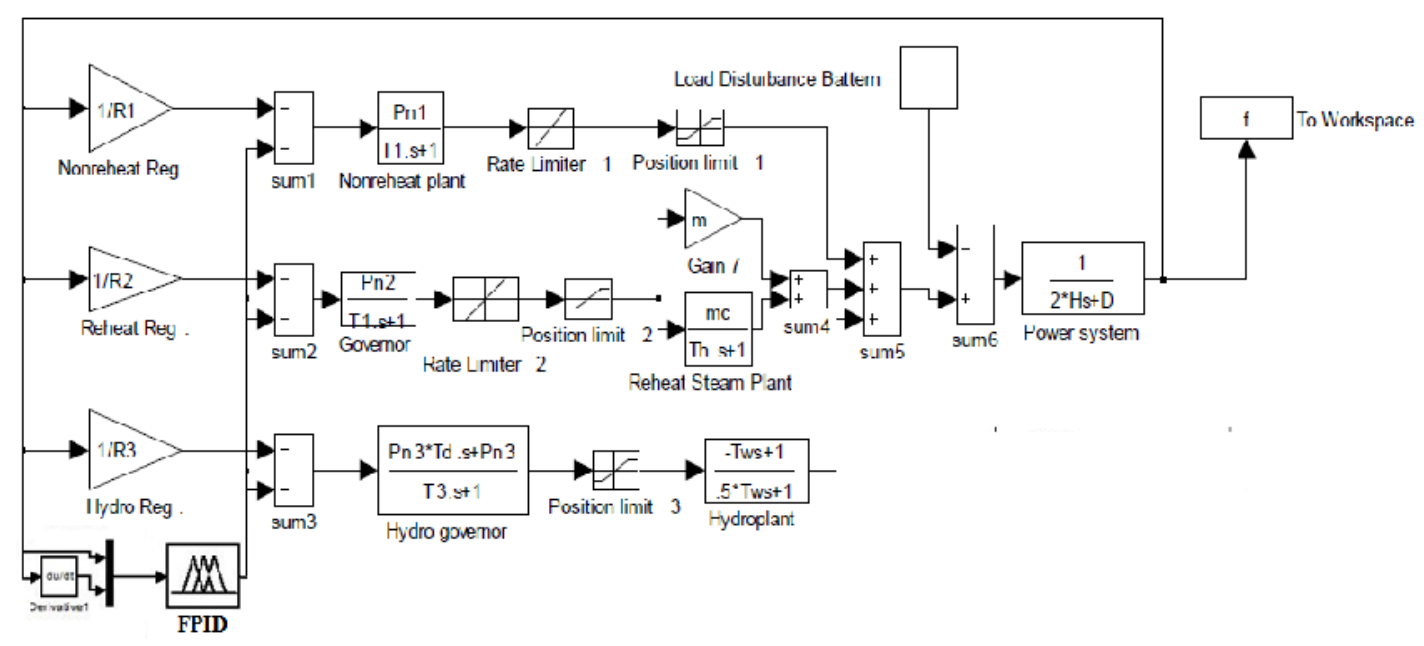

Figure (1): The block diagram of the Egyptian Power System LFC model in Simulink representation

Figure (1) shows the block diagram of the EPS LFC model using SIMULINK MATLAB [18, 20-23]. The parameters of this model are divided into two sets. The first set of parameters does not depend on the system operating conditions. Table (1) includes values of these parameters which have been estimated by NECC [20-23]. The second set of parameters varies with time according to the operating condition. The data required to calculate the parameters changing are concerned with the data of each generator including: status (ON or OFF), type of unit (non-reheat, reheat or hydro), unit rating (MW), unit output (MW) for the operating condition under study, inertia of the unit, and the spinning reserve of the unit in percentage of the unit rating. The Simulink model considers the generating rate constraints GRC for different generating units. The applied values for the GRC are $0.1 \mathrm{p} . \mathrm{u} \mathrm{MW} / \mathrm{min}$ and $0.2 \mathrm{p} . \mathrm{u} \mathrm{MW} / \mathrm{min}$ for reheat turbines and non-reheat turbines, respectively. The GRC of hydro plants is neglected since its actual value is much greater corresponding to the time durations of practical disturbances [2023]. 
Table (1): Egyptian LFC parameters

\begin{tabular}{|c|c|c|c|c|c|}
\hline Parameter & Value & Parameter & Value & Parameter & Value \\
\hline \hline $\mathrm{D}$ & 0.028 & $\mathrm{R}_{1}$ & 2.5 & $\mathrm{~T}_{\mathrm{w}}$ & 1.0 \\
\hline $\mathrm{T}_{1}$ & 0.4 & $\mathrm{R}_{2}$ & 2.5 & $\mathrm{R}_{\mathrm{L}}$ & 0.8 \\
\hline $\mathrm{T}_{2}$ & 0.4 & $\mathrm{R}_{3}$ & 1.0 & $\mathrm{~T}_{\mathrm{L}}$ & 2.5 \\
\hline $\mathrm{T}_{\mathrm{b}}$ & 6 & $\mathrm{~T}_{\mathrm{d}}$ & 5 & & \\
\hline $\mathrm{m}$ & 0.5 & $\mathrm{~T}_{3}$ & 90 & & \\
\hline
\end{tabular}

The dynamical equations of this model can be written in the state-space form given by

$$
\dot{\mathrm{x}}(\mathrm{t})=\mathrm{A} \mathrm{x}(\mathrm{t})+\mathrm{Bu}(\mathrm{t})
$$

where :

$$
\mathrm{x}(\mathrm{t})=\left[\begin{array}{lllllll}
\mathrm{F}(\mathrm{t}) & \mathrm{P}_{1}(\mathrm{t}) & \mathrm{P}_{2}(\mathrm{t}) & \mathrm{V}_{2} & \mathrm{P}_{3}(\mathrm{t}) & \mathrm{G}(\mathrm{t})
\end{array}\right]^{\mathrm{t}}
$$

and $\quad \mathrm{F}(\mathrm{t})=\mathrm{x}_{1}(\mathrm{t})$ is the incremental frequency deviation in $\mathrm{Hz}$, and

$\mathrm{P}_{1}(\mathrm{t})=\mathrm{x}_{2}(\mathrm{t})$ is the incremental change in non-reheat plant output in p.u MW.

$\mathrm{P}_{2}(\mathrm{t})=\mathrm{x}_{3}(\mathrm{t})$ is the incremental change in reheat plant output in p.u MW.

$\mathrm{V}_{2}=\mathrm{x}_{4}(\mathrm{t})$ is the incremental opening in steam valve of reheat plant output in p.u MW

$\mathrm{P}_{3}(\mathrm{t})=\mathrm{x}_{5}(\mathrm{t})$ is the incremental change in hydro plant output in p.u MW.

$\mathrm{G}(\mathrm{t})=\mathrm{x}_{6}(\mathrm{t})$ is the incremental opening in hydro plant inlet vane in p.u MW.

Four loading conditions of the EPS are considered to design the FPID controller. These four loading conditions represent the max and min loads in two daily load curves of the EPS in 2008 [20-23] which are the two days of the max water discharge Monday $30 / 6 / 2008$ and the minimum water discharge Tuesday 8/1/2008 from hydro power plants. Table (2) shows the calculated parameters for the four considered operating conditions. The average point of the four loading conditions is obtained from Table 2 . [20-23]. Based on the experience of the Egyptian Electricity Authority EEA in control centers dates and National Energy Control Center NECC [7-9], the program of the NECC considers only the effect of primary reserve concepts. The secondary loop based on the frequency signal is added to the Egyptian power system Simulink model to enable utilizing the effect of secondary reserve concepts. The secondary loop is a feedback FPID as seen in Fig (1). 
Table (2): Operating conditions of EPS at 2008

\begin{tabular}{|c|c|c|c|c|}
\hline & $\mathrm{H}$ & $\mathrm{P}_{\mathrm{n} 1}$ & $\mathrm{P}_{\mathrm{n} 2}$ & $\mathrm{P}_{\mathrm{n} 3}$ \\
\hline Condition 1 & 5.7096 & 0.2529 & 0.6107 & 0.1364 \\
\hline Condition 2 & 6.0168 & 0.3002 & 0.5200 & 0.1798 \\
\hline Condition 3 & 5.8552 & 0.2433 & 0.6179 & 0.1389 \\
\hline Condition 4 & 6.1452 & 0.3335 & 0.5455 & 0.1210 \\
\hline
\end{tabular}

\section{Fuzzy Controller Structure}

A fuzzy logic controller has four main components as shown in Fig (2) namely; fuzzification stage, inference mechanism, rule base and defuzzification stage. For the design process, the triangular membership function is chosen because of its simplicity and effectiveness. The peak value of a membership function is the point where the output is unity and the width is the distance to zero membership. The input variables, or process states in the fuzzy controller are named as: the error e(k) and the change in error [5-7].
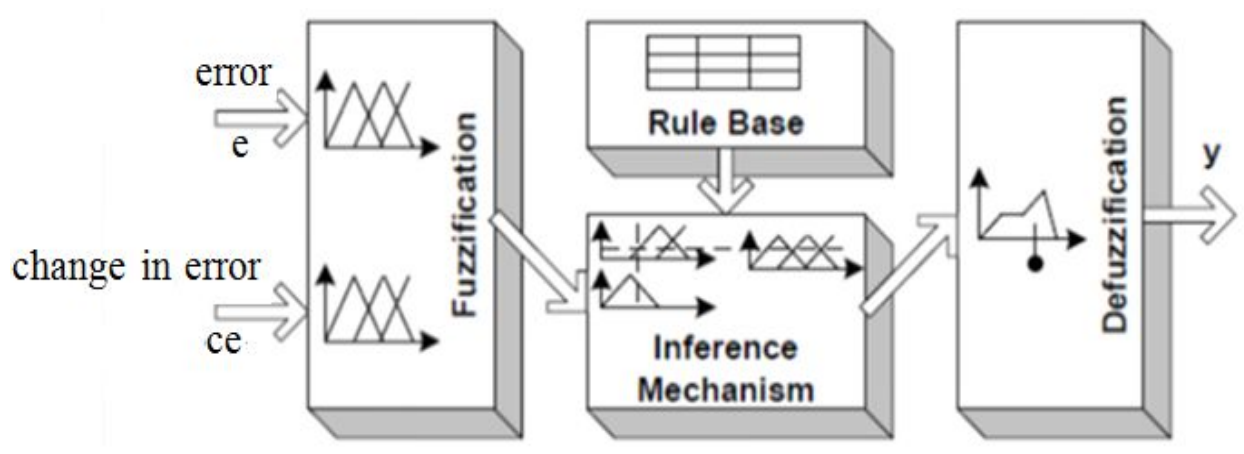

Figure (2): Structure of a fuzzy controller

The first step in the design strategy is to replace the known PID by a linear fuzzy PID, in other words, is to transfer the PID gains to the linear fuzzy controller. The conventional PID controller signal $u(n)$ at any given time instant $n$ can be expressed in either absolute as in Eqn. (2) or incremental form Eqn. (3) with respect to the feed-back error signal $\mathrm{e}(\mathrm{n})$ as follows:

$$
\begin{gathered}
u(n)=K_{p} e(n)+\frac{K_{D}}{T_{S}} e(n)+K_{I} \sum_{i=1}^{n} e(n) T_{s} \\
u(n)=K_{p} \quad e(n)+\frac{K_{D}}{T_{s}}{ }^{2} e(n)+K_{I} T_{S} e(n)
\end{gathered}
$$


Where, $\mathrm{T}_{s}$ is the sampling period and $\mathrm{Kp}, \mathrm{K}_{\mathrm{D}}$ and $\mathrm{K}_{\mathrm{I}}$ are the proportional, derivative and integral gains respectively. Also, $\mathrm{e}(\mathrm{n})=\mathrm{e}(\mathrm{n})-\mathrm{e}(\mathrm{n}-1)$ and ${ }^{2} \mathrm{e}(\mathrm{n})=\mathrm{e}(\mathrm{n})-\mathrm{e}(\mathrm{n}-1)$.

Based on the above, it is required to design fuzzy PD and fuzzy PI controllers. The design steps for any one of these controllers can be summarized as follows [8-12]:

For any one of the two controller types:

1- Place an equivalent conventional PD or PI to control the process and get the values of the gains $\mathrm{K}_{\mathrm{P}}, \mathrm{K}_{\mathrm{I}}$ and $\mathrm{K}_{\mathrm{D}}$ using any control design technique.

2- Construct an alternative linear 2-input fuzzy PD or fuzzy PI control having the error and error change signals $\mathrm{E}, \mathrm{CE}$ as the inputs.

3 - Normalize the two inputs to any universe of discourse, for example [-1 1$]$, by placing two normalizing input gains GE and GCE that convert the maximum values of the input signals to the values of the chosen universe of discourse.

4- Construct a linear surface 2-input fuzzy controller and choose the ranges for the two inputs to be the same as the universe of discourse to which the original inputs where normalized [-1 1 1] tanking the output membership range as the sum of the two ranges of the inputs, i.e., $\left[\begin{array}{ll}-2 & 2\end{array}\right]$.

5- The input sets are uniformly distributed triangular and cross neighbor sets at membership value of 0.5 so that any crisp value is defined in two fuzzy sets, and the output membership functions is taken to be uniformly distributed singletons for the simplicity of defuzzification.

6- Divide the two input membership domains to only three areas: negative, zero and positive.

7- Write the rule base that has to represent a linear surface as given in Table (3).

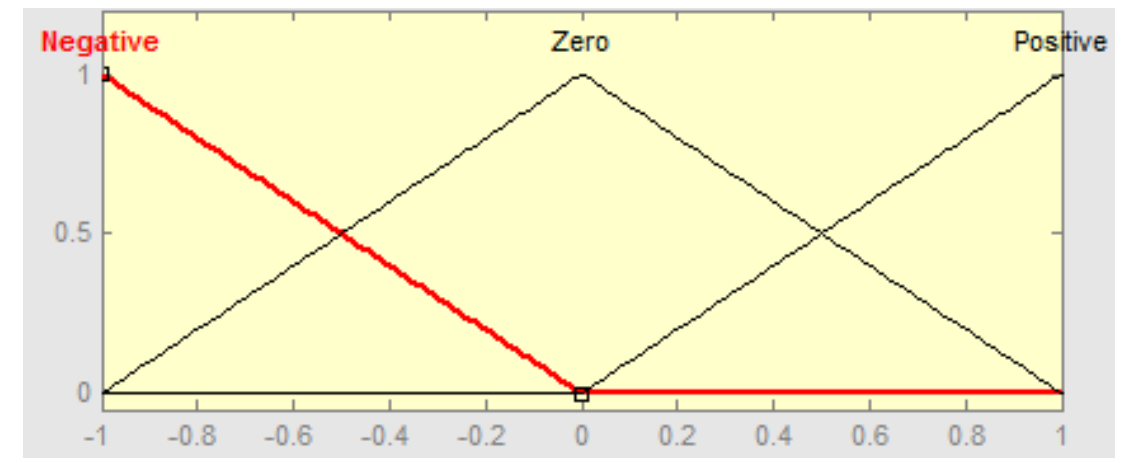

Figure (3): Input memberships $E$ and $C E$ 
Proceedings of the $\mathbf{9}^{\text {th }}$ ICEENG Conference, 27-29 May, 2014

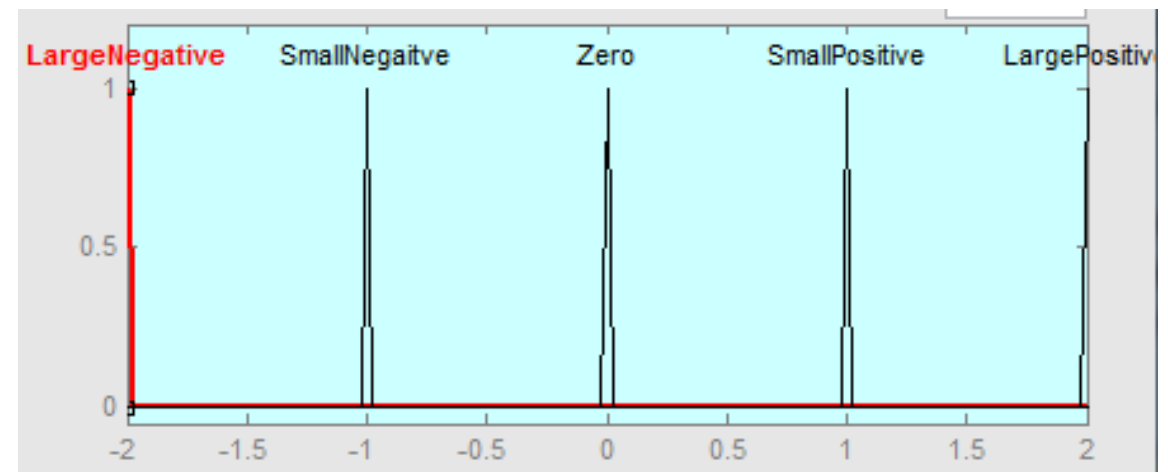

Figure (4): Output membership

Table (3): Fuzzy rule base

\begin{tabular}{|l|c|c|c|}
\hline \multicolumn{1}{|r|}{ CE } & Negative & Zero & Positive \\
\hline $\begin{array}{l}\text { Negativ } \\
\text { e }\end{array}$ & Large Negative & Small Negative & Zero \\
\hline Zero & Small Negative & Zero & Small Positive \\
\hline Positive & Zero & Small Positive & Large Positive \\
\hline
\end{tabular}

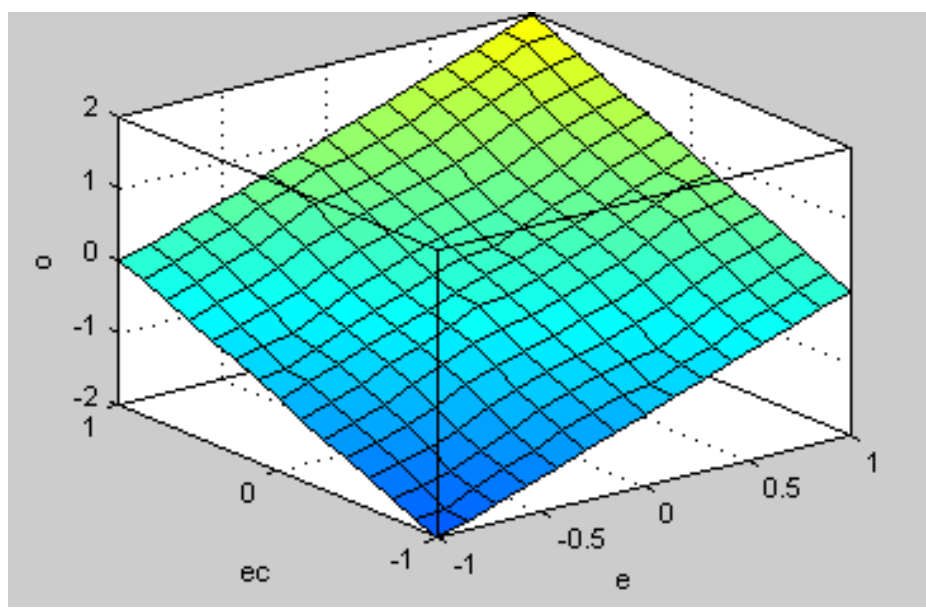

Figure (5): Fuzzy rule base surface

The method of the defuzzification process converts the fuzzy output to crisp value to be used as a non fuzzy control action is chosen to be the most popular defuzzification 
method as the center of gravity or center of area which is formulated as follows:

$$
\mathrm{u}=\frac{\sum_{\mathrm{i}=1}^{\mathrm{r}} \mathrm{u}\left(\mathrm{u}_{\mathrm{i}}\right) \mathrm{u}_{\mathrm{i}}}{\sum_{\mathrm{i}=1}^{\mathrm{u}} \mathrm{u}\left(\mathrm{u}_{\mathrm{i}}\right)}
$$

Where $u\left(u_{i}\right)$ is the membership grad or weight of the element $u_{i}$ which is the output of the rule $\mathrm{i}$.

\subsection{Design steps for a fuzzy PD controller}

The fuzzy PD (FPD) controller has three gains, which are mainly for tuning the response, and they can also be used for scaling the input signal on to the input universe to exploit it better, where the crisp proportional derivative controller has only two gains which make it flexible and better. The typical structure of FPD controller shown in Fig (6), has two inputs [10-12]; the error signal ' $e$ ' and the change of the error 'de/dt'. The first input will be transformed from value 'e' into the value ' $E$ ' after multiplication with the error gain GE.

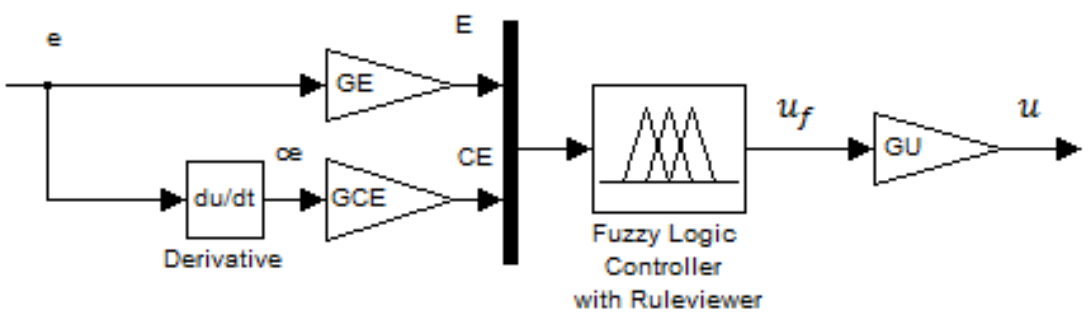

Figure (6): PD fuzzy controller

$$
\mathrm{E}=\mathrm{GE} * \mathrm{e}
$$

By the same procedure, the second input will be transformed from value 'de/dt' into the value of $\mathrm{CE}$ after multiplication with the change of error gain GCE.

$$
\mathrm{CE}=\mathrm{GCE} * \mathrm{de} / \mathrm{dt}
$$

The two fuzzy inputs ' $\mathrm{E}$ ' and 'CE' are processed by the rule base stage to produce the new fuzzy variable ' $u$ ' which will be transformed into the value ' $U$ ' after multiplication with the output gain GU.

$$
\mathrm{U}=\mathrm{GU} * \mathrm{u}
$$

Although the controller needs both the error and the change of error as inputs, the controller is single-input-single-output SISO, because in principle the inputs are formed from the error measurement single feedback loop. The control signal U(n), at the time instant $\mathrm{n}$, is a nonlinear function of error and change in error,

$$
\mathrm{U}(\mathrm{n})=f(\mathrm{GE} * \mathrm{e}(\mathrm{n}), \mathrm{GCE} * \mathrm{e}(\mathrm{n})) * \mathrm{GU}
$$


As the function $f$ is the rule base mapping, with two inputs and one output, the inputoutput mapping is a surface. A linear approximation requires the following conditions [10-12]:

- Support sets of input linguistic variables must be large enough so that input values stay in limits.

- Linguistic values must consist of symmetric triangular fuzzy sets that intercept with neighboring sets at a membership value of so that for any time instant, membership values add to 1 .

- Rule base must consist of and combinations of all fuzzy sets.

- Output linguistic variables must consist of fuzzy sets positioned at the sum of the peak positions of input fuzzy sets.

- The activation operator and should be multiplication and defuzzification method must be "centre of gravity" COG.

This will result in [10]:

$$
f(\mathrm{GE} * \mathrm{e}(\mathrm{n}), \mathrm{GCE} * \mathrm{e}(\mathrm{n}))=(\mathrm{GE} * \mathrm{e}(\mathrm{n})+\mathrm{GCE} * \mathrm{e}(\mathrm{n}))
$$

Then the control action for the linear controller is:

$$
\begin{aligned}
\mathrm{U}(\mathrm{n}) & =(\mathrm{GE} * \mathrm{e}(\mathrm{n})+\mathrm{GCE} * \mathrm{e}(\mathrm{n})) * \mathrm{GU} \\
& =\mathrm{GE} * \mathrm{GU} *\left(\mathrm{e}(\mathrm{n})+\frac{\mathrm{GCE}}{\mathrm{GE}} * \mathrm{e}(\mathrm{n})\right)
\end{aligned}
$$

The ideal continuous PD controller is given by:

$$
\mathrm{U}(\mathrm{n})=\mathrm{K}_{\mathrm{p}}\left(\mathrm{e}(\mathrm{n})+\mathrm{T}_{\mathrm{d}} * \frac{\mathrm{de}(\mathrm{n})}{\mathrm{dt}}\right)
$$

Where $u$ is the controller output, $\mathrm{K}_{\mathrm{p}}$ is the proportional gain, $\mathrm{e}$ is the error between the reference signal and the actual signal y $(\mathrm{e}=\operatorname{Ref}-\mathrm{y})$ and $\mathrm{T}_{\mathrm{d}}$ is the derivative time $\left(T_{d}=k_{d} / k_{p}\right)$. Comparing Equations, the gains are related as follows:

$$
\begin{aligned}
& \mathrm{Kp}=\mathrm{GE} * \mathrm{GU} \\
& \mathrm{Td}=\mathrm{GCE} / \mathrm{GE} \\
& \mathrm{Kd}=\mathrm{GCE} * \mathrm{GU}
\end{aligned}
$$

Comparing (8) with (5), one get:

Table (4): Parameters of controller gains and FLC gains

\begin{tabular}{|c|c|}
\hline Conventional Gain Parameter & Value in terms of FLC gains \\
\hline $\mathrm{K}_{\mathrm{P}}$ & $\mathrm{GE} * \mathrm{GU}$ \\
\hline $\mathrm{K}_{\mathrm{d}}$ & $\mathrm{GCE} * \mathrm{GU}$ \\
\hline
\end{tabular}


Calculate GE to normalize the error value as:

$$
\mathrm{GE}=\frac{\text { Fuzzy membership boundary values of error }}{\max (\text { error crisp value })}
$$

\subsection{Design steps for a fuzzy PI controller}

By the same way as proposed in [10-12] the FPI control can be obtained from Fig (7) and FPI gains are tabulated in Table (5).

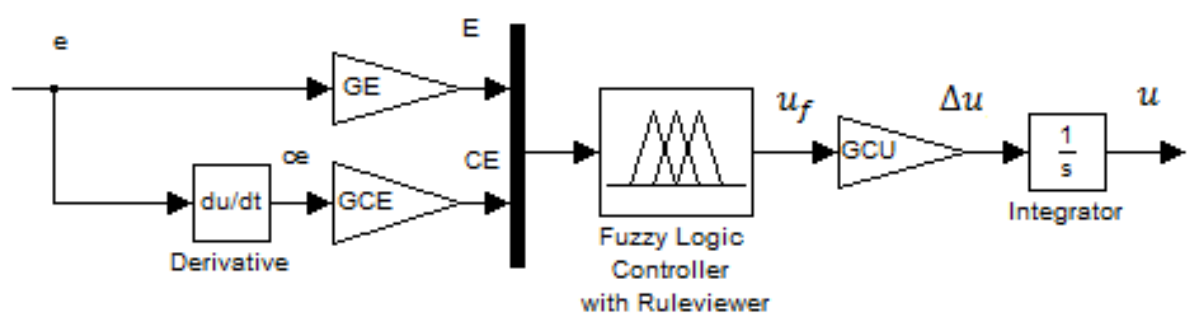

Figure (6): PI fuzzy controller

Table (5): Parameters of controller gains and FLC gains

\begin{tabular}{|c|c|}
\hline Conventional Gain Parameter & Value in terms of FLC gains \\
\hline $\mathrm{K}_{\mathrm{P}}$ & $\mathrm{GEC}^{*} \mathrm{GCU}$ \\
\hline $\mathrm{K}_{\mathrm{I}}$ & $\mathrm{GE} * \mathrm{GCU}$ \\
\hline
\end{tabular}

Calculate GE to normalize the error value as:

$$
\begin{aligned}
& \text { 1- GE }=\frac{\text { Fuzzy membership boundary values of error }}{\max (\text { error crisp value })} \\
& \text { 2- } \mathrm{GCU}=\mathrm{K}_{1} / \mathrm{GE} \\
& \text { 3- } \mathrm{GCE}=\mathrm{K}_{\mathrm{P}} / \mathrm{GCU}
\end{aligned}
$$

\subsection{Design steps for a fuzzy PID controller}

For designing a PID fuzzy controller, it is straight forward to envision a fuzzy PID controller with two input terms: error, derivative error. This can be obtained by using a hybrid action of both FPI and FPD actions as follows [10-12]: 


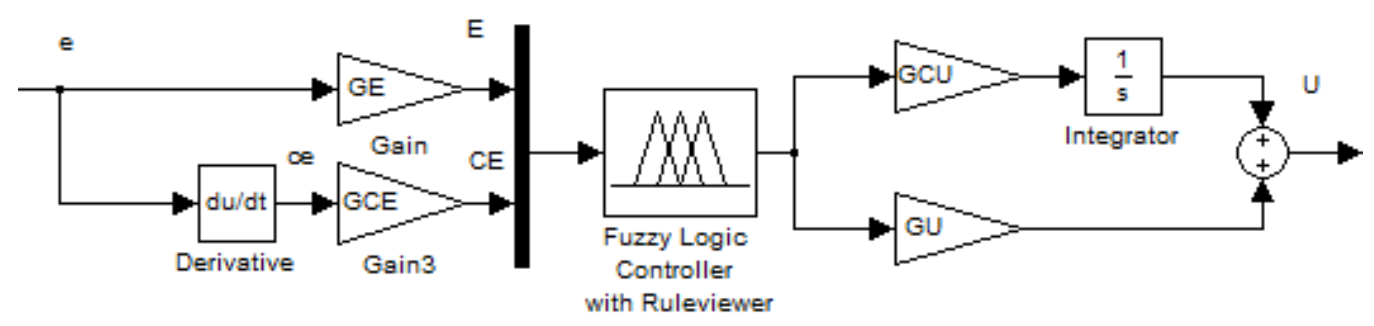

Figure (8) : Fuzzy PID model

1- Regarding the two gains of $K_{I}$ and $K_{d}$, they will not differ from those of the abovementioned PD and PI controllers, while the overall $K_{P}$ will be the summation of the $K_{P}$ values for both PD and PI.

$$
\mathrm{u}(\mathrm{n})=\mathrm{GCU} \sum_{\mathrm{i}=0}^{\mathrm{n}} \mathrm{u}(\mathrm{i})+\mathrm{GU} \mathrm{u}(\mathrm{n})
$$

Table (6) depicts the relation between the conventional gain parameters of the PID controllers and the value of the FLC gains of FPID controller.

Table (6) : Parameters of controller gains and FLC gains

\begin{tabular}{|c|c|}
\hline Conventional Gain Parameter & Value in terms of FLC gains \\
\hline $\mathbf{K}_{\mathbf{P}}$ & $\mathrm{GE} * \mathrm{GU}+\mathrm{GEC} * \mathrm{GCU}$ \\
\hline $\mathbf{K}_{\mathbf{I}}$ & $\mathrm{GE} * \mathrm{GCU}$ \\
\hline $\mathbf{K}_{\mathbf{d}}$ & $\mathrm{GCE} * \mathrm{GU}$ \\
\hline
\end{tabular}

The calculate value of GE to normalize the error is given by:

$1-\mathrm{GE}=\frac{\text { Fuzzy membership boundary values of error }}{\max (\text { error crisp value })}$

2- $\mathrm{GCU}=\mathrm{K}_{1} / \mathrm{GE}$

3- $\mathrm{GCE}=\mathrm{GE}\left(\frac{\sqrt{\mathrm{K}_{\mathrm{p}}^{2}-4 \mathrm{~K}_{\mathrm{I}} \mathrm{K}_{\mathrm{D}}}}{2 \mathrm{~K}_{\mathrm{I}}}\right.$

4- $\mathrm{GU}=\mathrm{K}_{\mathrm{P}} / \mathrm{GCE}$ 


\section{Relative Rate Observer Based Self-tuning of Two-input FPID Controller}

The previous structural parameters include $\mathrm{I} / \mathrm{O}$ variables to fuzzy inference, fuzzy linguistic sets, membership functions, fuzzy rules, inference mechanism and defuzzification mechanism. The structural parameters are usually determined during offline design while the tuning parameters can be calculated during on-line adjustments of the controller to enhance the process performance, as well as to accommodate the adaptive capability to system uncertainty and process disturbance [13].

Tuning parameters include $\mathrm{I} / \mathrm{O}$ scaling factors SF and parameters of membership functions MF. The relative rate observer idea given in [13]. Fig (9) shows the Relative Rate Observer Self-tuning RROST method. This method adjusts the scaling factors that correspond to the derivative and integral coefficients of the fuzzy PID controller using a fuzzy inference mechanism in an on-line manner. The fuzzy inference mechanism that adjusts the related coefficients has two inputs one of which is "system error" designated as $\mathbf{e}$ and the other one is a new variable $\mathbf{r}_{\mathbf{v}}$ named as "normalized acceleration". The normalized acceleration gives "relative rate" information about the fastness or slowness of the system response. The normalized acceleration $r_{v}(k)$ is defined as [13]:

$$
\mathrm{r}_{\mathrm{v}}(\mathrm{k})=\frac{\mathrm{d} \mathrm{e}(\mathrm{k})-\mathrm{de}(\mathrm{k}-1)}{\mathrm{de}(.)}=\frac{\mathrm{dd} \mathrm{e}(\mathrm{k})}{\mathrm{de}(.)}
$$

Here, $\mathrm{d} e(\mathrm{k})$ is the change in error and it is given by:

$$
\mathrm{de}(\mathrm{k})=\mathrm{e}(\mathrm{k})-\mathrm{e}(\mathrm{k}-1)
$$

and $\mathrm{dd} \mathrm{e}(\mathrm{k})$ is called the acceleration in error and it is given by:

$$
\mathrm{dd} \mathrm{e}(\mathrm{k})=\mathrm{de}(\mathrm{k})-\mathrm{de}(\mathrm{k}-1)
$$

also, $\mathrm{d} \mathrm{e}($.$) is chosen as follows:$

$$
\mathrm{de}(.)= \begin{cases}\mathrm{de}(\mathrm{k}) & \text { if }|\mathrm{de}(\mathrm{k})| \geq|\mathrm{de}(\mathrm{k}-1)| \\ \mathrm{de}(\mathrm{k}-1) & \text { if }|\mathrm{de}(\mathrm{k})| \leq|\mathrm{de}(\mathrm{k}-1)|\end{cases}
$$

The output of the fuzzy parameter regulator is designated as $\gamma$ and the scaling factors GCE and GCU are adjusted as follows:

$$
\begin{aligned}
& \mathrm{GCE}=\mathrm{GCE}_{\mathrm{s}} \cdot \mathrm{K}_{\mathrm{fd}} \cdot \mathrm{K}_{\mathrm{f}} \cdot \gamma \\
& \mathrm{GCU}=\frac{\mathrm{GCU}_{\mathrm{s}}}{\mathrm{K}_{\mathrm{f}} \cdot \gamma}
\end{aligned}
$$




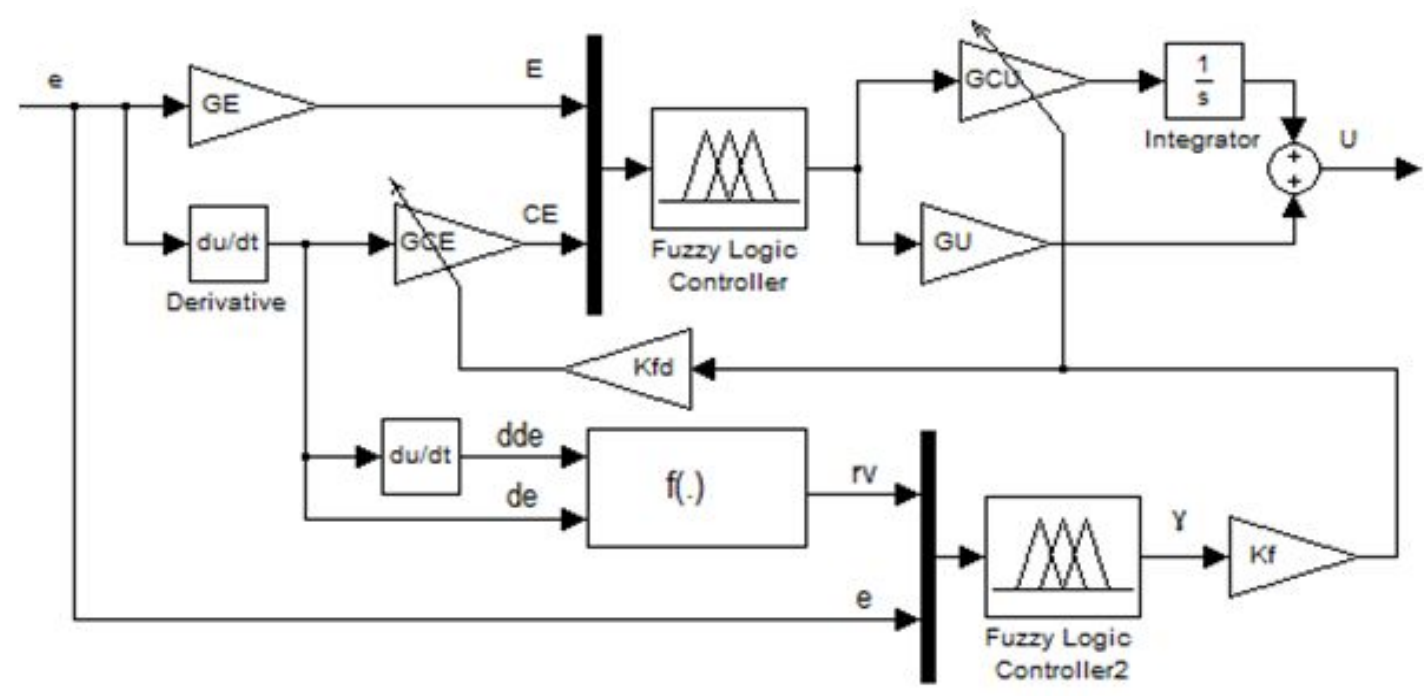

Figure (9) : Relative rate self tuning for PID-type FLC

The fuzzy rules of the FLC, according to [13] are as follows:

Table (7) : Relative rate observer FLC rule matrix

\begin{tabular}{|c|c|c|c|}
\hline$|\mathbf{e}| \quad \mathbf{r}_{\mathbf{v}}$ & $\mathbf{S}$ & $\mathbf{M}$ & $\mathbf{F}$ \\
\hline $\mathbf{S}$ & M & $\mathrm{M}$ & $\mathrm{L}$ \\
\hline SM & SM & $\mathrm{M}$ & $\mathrm{L}$ \\
\hline $\mathbf{M}$ & $S$ & SM & $\mathrm{M}$ \\
\hline $\mathbf{L}$ & $S$ & $\mathrm{~S}$ & SM \\
\hline
\end{tabular}

The input and output memberships are depicted in Fig (10), Fig (11) and Fig (12).
L: large;
$\mathrm{M}$ :medium;
$\mathrm{SM}:$ small medium;
$\mathrm{S}:$ small

For the other input variable rv the following linguistic levels are assigned:
$\mathrm{F}:$ fast;
$\mathrm{M}$ : moderate;
S : slow

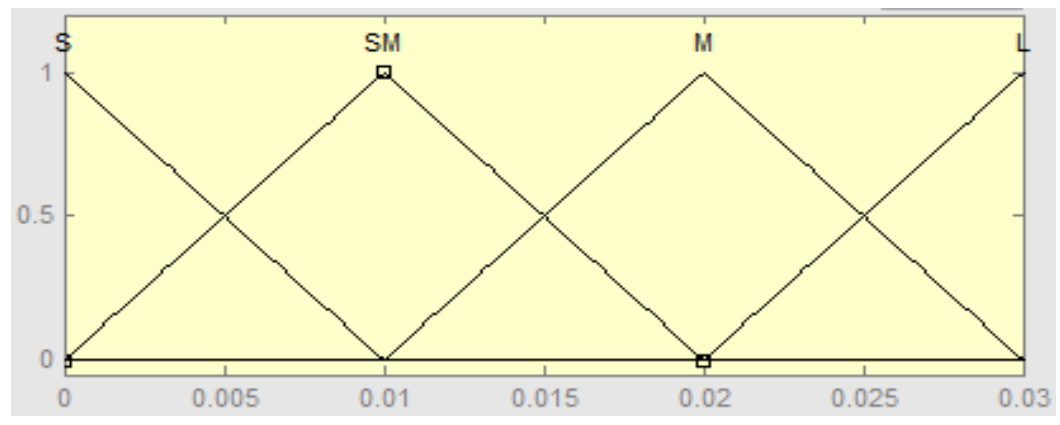

Figure (10): Relative rate observer FLC input membaership for error signal e 


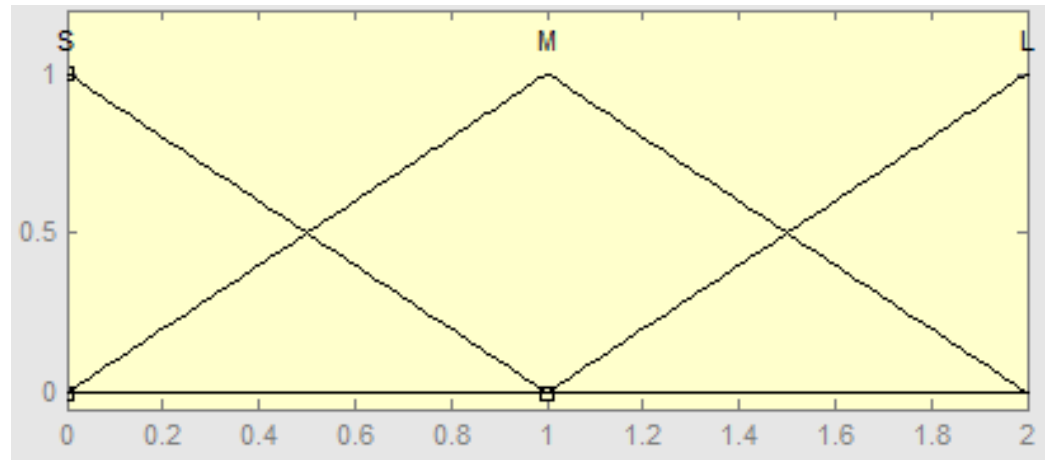

Figure (11): Relative rate observer FLC input membaership for relative rate signal $r$

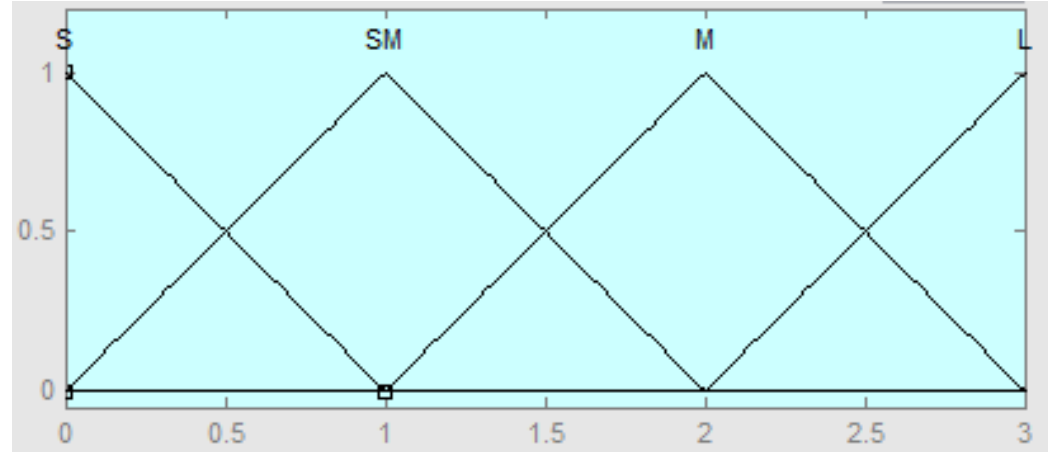

Figure (12): Relative rate observer FLC output membaership

The advantage of this method over the peak oberver method is that there is no need to keep the first peak unchanged $[24,25]$.

\section{Simulation Results}

The simulation is done using MATLAB Platform. The LFC system comprises three power plants; non-reheat, reheat and hydro generation plants as shown in Fig (1). Several cases are performed for the proposed FPID controller self tuned by RRO method with system nonlinearly for verification of the effectiveness of the proposed controllers. The nonlinearity is represented by a Generated Rate Constraint GRC. The simulation results are started in all cases by comparing the responses of the controlled system by a PID obtained using ant colony optimization system for LFC-EPS [18] and the respective responses after replace it with FPID. It should be notced that the PID gains used are those found with nominal system parameters. The values of the PID gains were $k_{p}=1.9192, k_{i}=0.15152$ and $\mathrm{k}_{\mathrm{d}}=0.5555$ [18]. It is denoted by ACS-PID. It is observed that responses of the FPID almost exactly the same responses of ACS-PID to verify that the design procedure is correct. 


\section{Case 1: Step disturbance $\boldsymbol{P}_{d}=1 \%$}

To test the effectiveness of the system equipped with the designed FPID- RRO controller, the system is subjected to an increase by $1 \%$ in $\mathrm{P}_{\mathrm{d}}$. The time response of the frequency deviation $\mathrm{F}$ and the control input are displayed in Fig (13). Clearly, the FPID-RRO shows good performance characterized by lower undershoot, less oscillations and faster response. The control input using FPID has maximum starting value with loss overshoot. The responses of ACS-PID and the respective responses by FPID are almost the same.

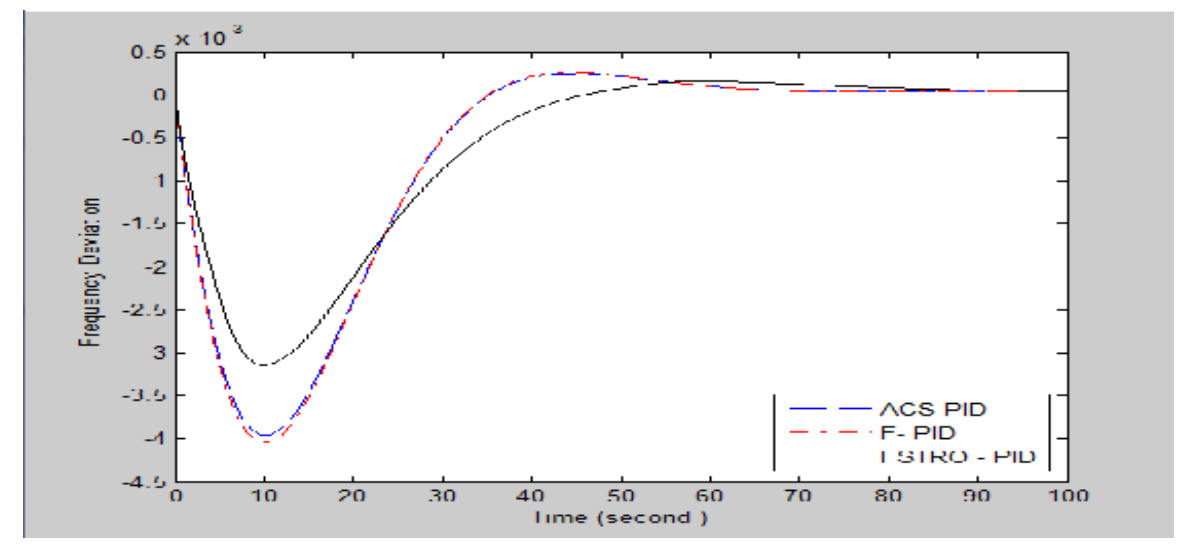

(a) - Frequency deviation

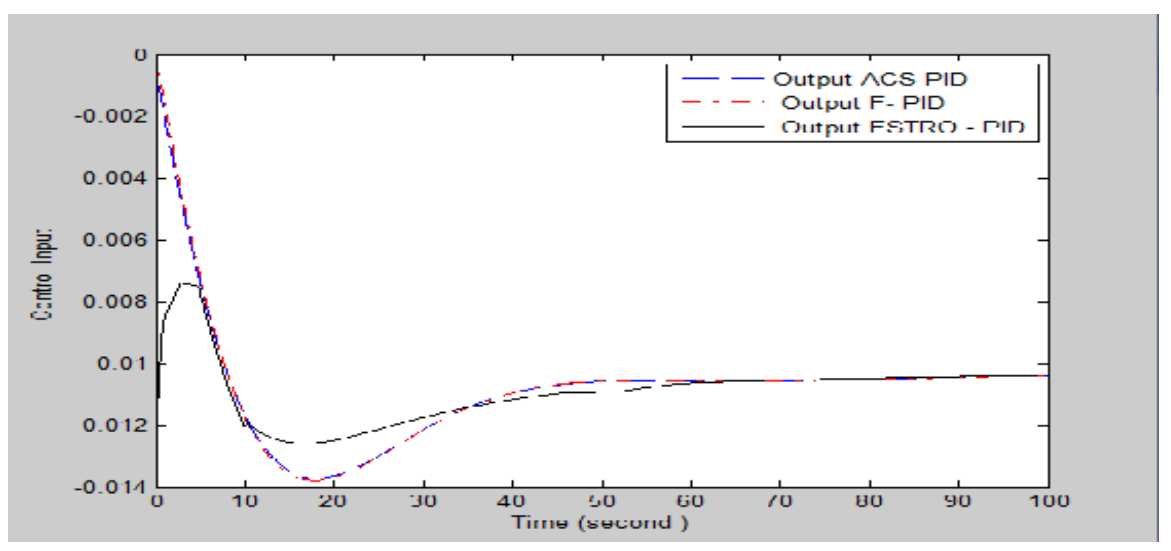

(b) - Control input

Figure (13) : Dynamic performance of EPS associated with step disturbance

\section{Case 2: Disturbance variations}

The system is subjected to the disturbance shown in Fig (14) - a. It is observed that the controlled system with FPID-RRO has lower undershoot and smooth responses as compared to a relatively larger undershoot exhibited by FPID with heavy oscillations. 
Fig (14) - b and - c show the verification of the effectiveness of the FPID-RRO for the frequency deviation $\mathrm{F}$ and the control input. The control input using FPID and FPIDRRO give better responses.

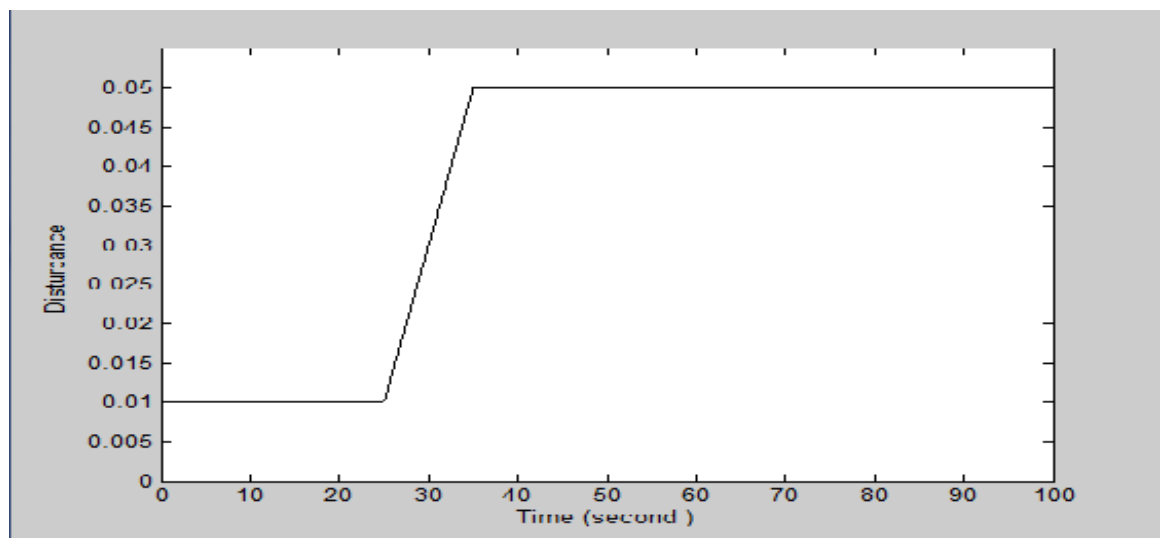

(a) - Disturbance

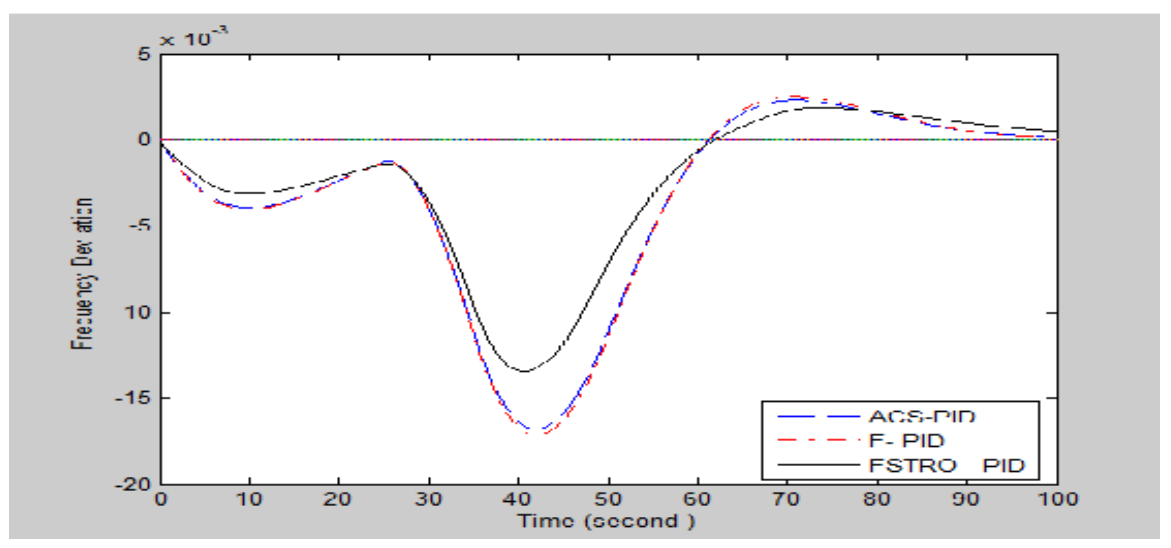

(b) - Frequency deviation

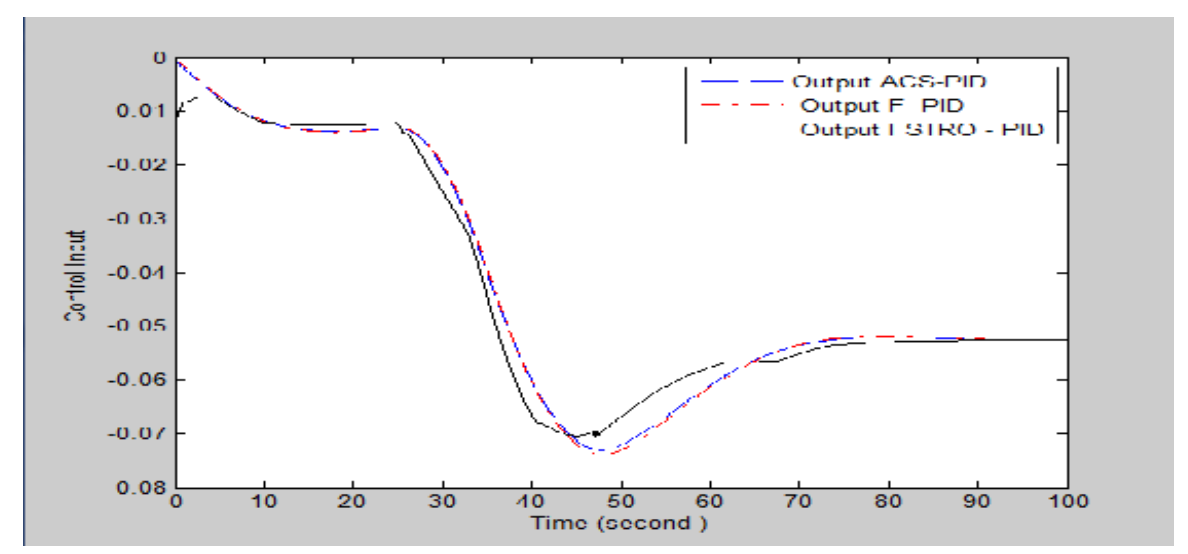

(c) - Control input

Figure (14) : Dynamic performance of EPS associated with disturbance variation 


\section{Case 3: Tracking Disturbance Variations}

Comparison between the performances of the proposed FPID-RRO and FPID controllers when the system is subjected to the tracking disturbance variations is shown in Fig (15). It can be noticed that the controllers show acceptable performance. Also, it is clearly shown that the FPID-RRO has few oscillations and relatively short settling time while FPID controller has large undershoot with a longer settling time. The control input for the two controllers give satisfactory results.

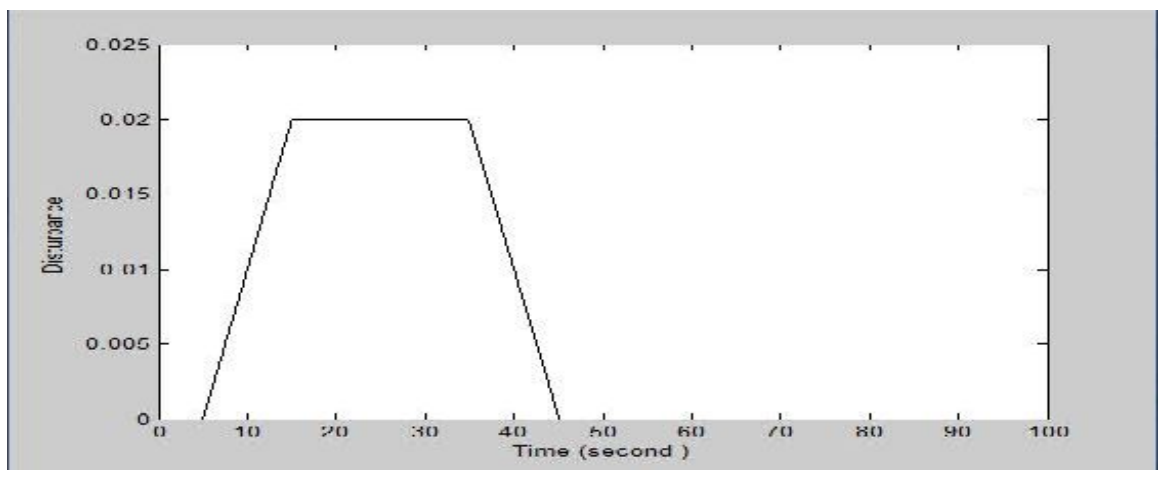

(a) - Disturbance

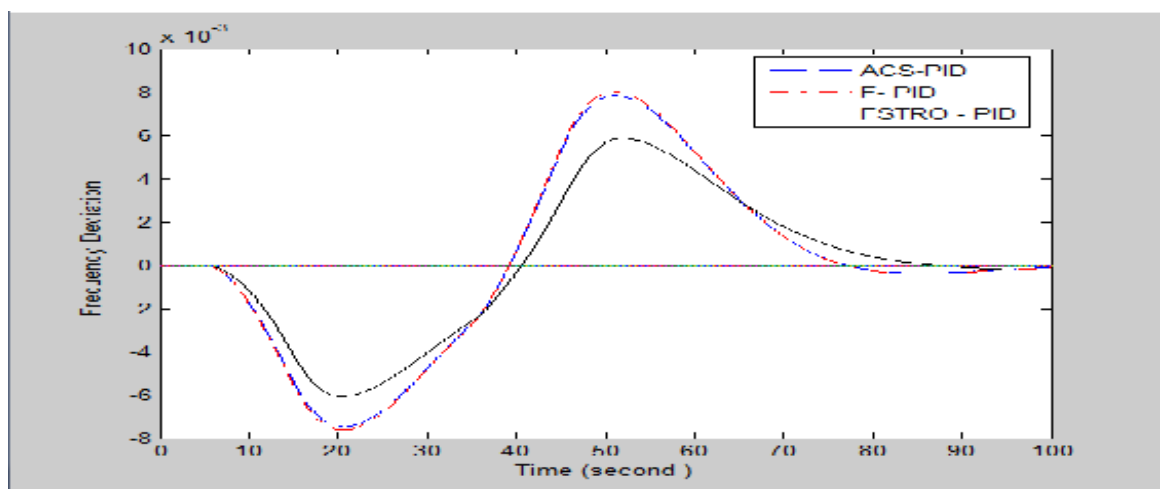

(b) - Frequency deviation

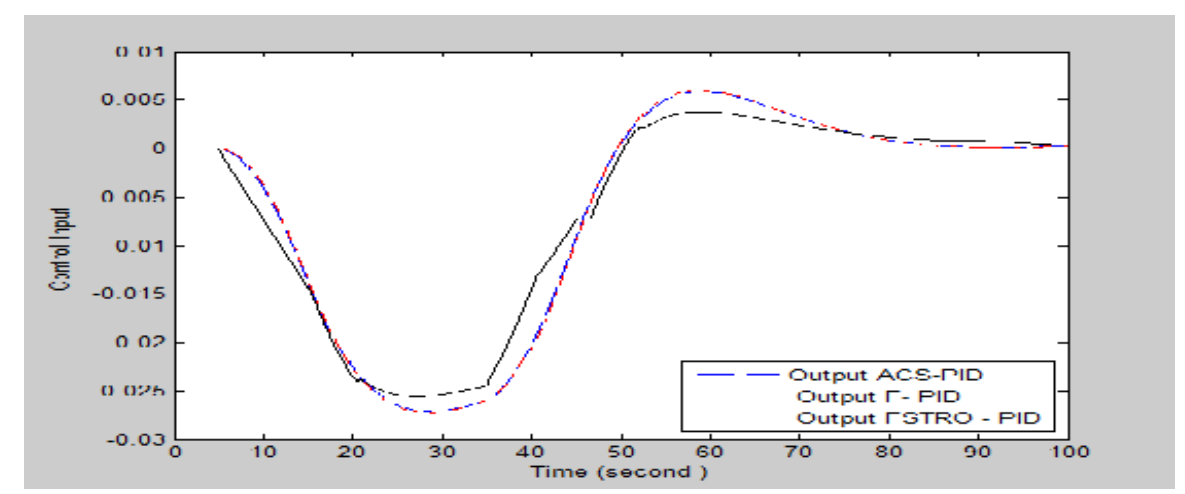

(c) - Control input

Figure (15) : Dynamic performance of EPS associated with tracking disturbance 


\section{Case 4: System Parameters variation}

The parameters $D, R_{1}, R_{2}, R_{3}, T_{1}, T_{2}, T_{3}, T_{w}, T_{h}$ and $T_{d}$ are taken into account as parameters to be changed with $40 \%$ from their normal values in EPS [19]. The simulation results are shown in Fig (16) - b and - $\mathrm{c}$ when the system is subjected to the disturbance shown in Fig (16) - a. For the proposed FPID-RRO and FPID the system is shown to respond robustly to such parameter variations with the presence of the nonlinearity GRC. The FPID-RRO still give better responses than FPID in smaller undershoot and settling time fulfills its requirement to self tuning of FPID. The control input using the two controls still give better results. Finally, results obtained by the FPID-RRO are very encouraging in the presence of system nonlinearity and parameter variations than FPID.

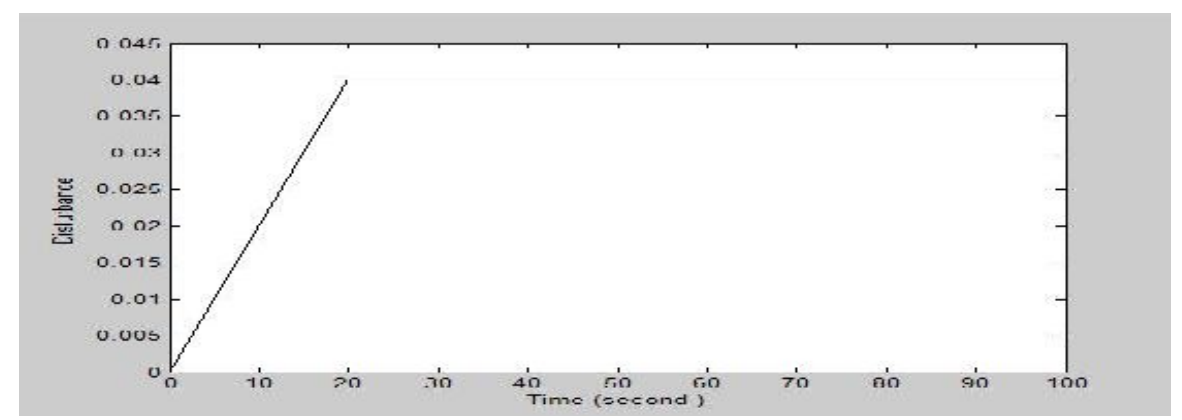

(a) - Disturbance

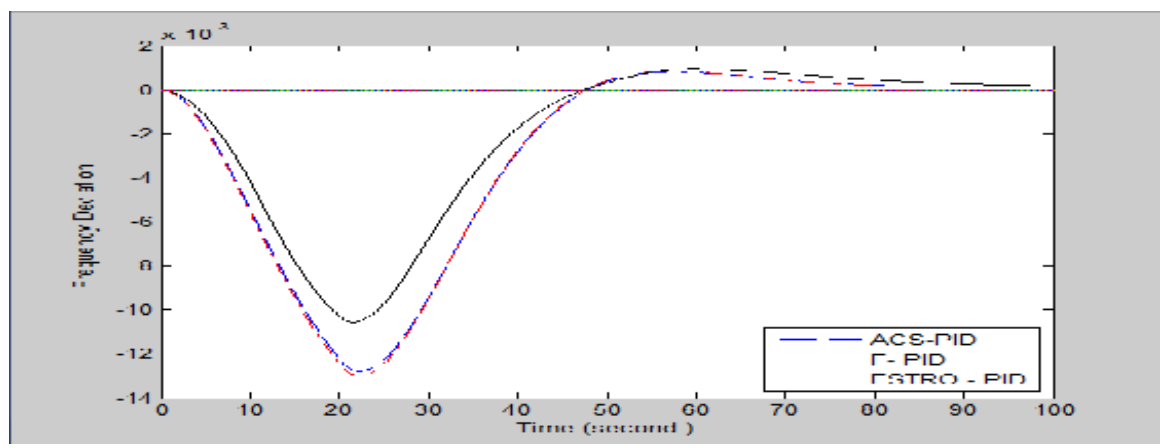

(b) - Frequency deviation

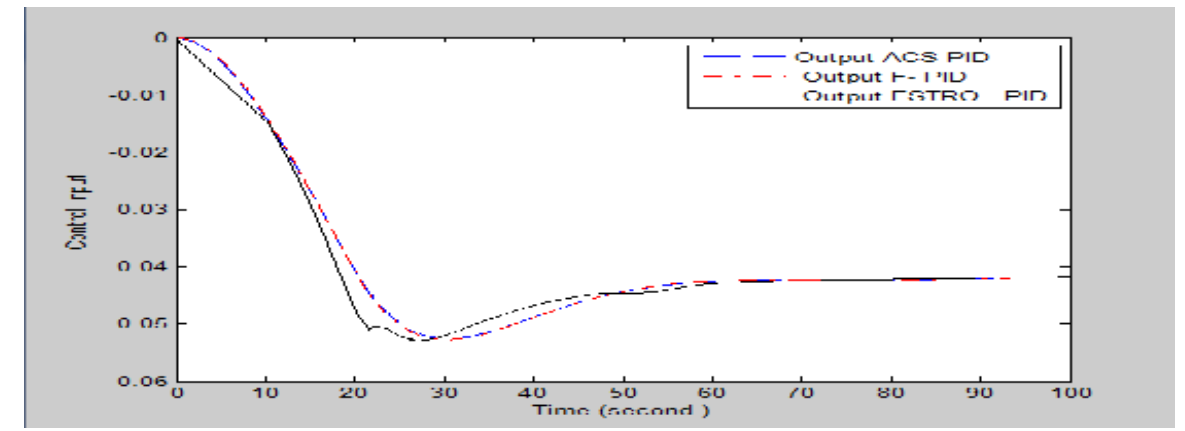

(c) - Control input

Fig. 16 Dynamic performance of power system 


\section{Conclusions:}

This paper has presented the design steps and a comparison for two controllers. Firstly, FPID is designed based on PID controller with known gain values. Secondly, self tuning is designed for FPID based on RRO method. The proposed designed controllers were applied to the LFC of the EPS as a single area with multi unit power system. The effectiveness of proposed controllers has been verified for diverse disturbances and parameters' change in the presence of the system inherent nonlinearity GRC. The results prove that the proposed controllers FPID and FPID-RRO satisfy the LFC system requirements and show a good performance during regulation and reference tracking disturbances. Simulation results have demonstrated the FPID-RRO is more effective than FPID controller as follows:

1. Improving the transients with fast removal of steady-state error, less oscillations and fast settling time

2. Presenting good performance under parameters' change and system nonlinearity.

\section{References:}

[1] H. Shayeghi, H.A. Shayanfar and A. Jalili, Load Frequency Control Strategies: A State-of-the-Art Survey for the Researcher, Energy Conversion and Management, Vol. 49, P. 344-353, 2008.

[2] G.J. Silva, A.Datta, et al., "New results on the synthesis of PID controllers," IEEE Transactions on Automatic Control, 2002, 47(2), pp. 241-252.

[3] Kim, Dong Hwa, "Robust PID controller tuning of multivarlable system using clonal selection and fuzzy logic," in Proceedings of the SICE 2005 Annual Conference, Okayama, 2005, pp. 734-739.

[4] H. Onishi, S. Shibasaki and S. Iwamoto" A new PID gain determination for the LFC Control Design System" IEEE, IPEC, pp. 146-151, 2010.

[5] K. Tanaka and H. Wang, "Fuzzy Control Systems Design and Analysis: A Linear Matrix Inequality Approach", New York: Wiley, 2001

[6] G.R.Chen and T.T.Pham, "Introduction to fuzzy sets, fuzzy logic, fuzzy control system",CRC.Press,Boac Raton,FL,USA,2000.

[7] Tang, K.L., Mulholland, R.J., Comparing fuzzy logic with classical controller designs IEEE Trans on Systems, Man, and Cybernetics 17(6), 1987,pp. 10851087.

[8] M. Mizumoto, "Realization of PID Controls By Fuzzy Control Methods," IEEE 1992. 
[9] L. Zheng, "A Practical Guide to Tune of Proportional and Integral (PI) Like Fuzzy Controllers," IEEE 1992.

[10] G. Chen, "Conventional and Fuzzy PID Controllers: An Overview", Int. J. of Intelligent Control and Systems, Vol. 1, pp. 235-246, 1996.

[11] G.K.I. Mann and R.G. Gosine ,"Fuzzy PID Controller Structures" CCECE' IEEE, pp. 187-791, 1997.

[12] G.K.I. Mann and R.G. Gosine, "Analysis and Performance Evaluation of LinearLike Fuzzy PI and PID Controllers IEEE, pp. 383-390, 1997.

[13] O. Karakal, E. Yesil, M. G"U Zelkaya, and I. Eksin," Implementation of a New Self-Tuning Fuzzy PID Controller on PLC", Turk Journal of Elec. Eng. , VoL.13, No.2 , pp. 277-286, 2005.

[14] M. A. Abdel Ghany, M. E. Bahgat,, W. M. Refaey and F. N. Hassan " Design Fuzzy Self Tuning of Optimal PID Load Frequency Controller for the Egyptian Power System" to be published in Ain Shams Journal of Electrical Engineering.

[15] Daneshfar F. and Bevrani H. "Load-Frequency Control: a GA-Based Multi-Agent Reinforcement Learning”, IET Generation, Transmission \& Distribution, Vol. 4, Iss. 1, pp 13-26, 2010.

[16] A. Bensenouci, A. M. Abdel Ghany, M. N. Said-Ahmad and S. A. Alghamdi, "Neuro- Genetic Adaptive Discrete-Time Load Frequency Control For an Interconnected Multi-Area Power System" Paper No. 320, published at the AMSE Journal, France, 2002.

[17] M. E. Bahgat, M. M. K. Saleh and A.M. Abdel Ghany " Design of Discrete Output FeedbackControl for a Hydrothermal Power System Using Simulated Annealing Algorithm", "Ain Shams Journal of Electrical Engineering, ., Vol. 1, pp. 153-163, June, 2009.

[18] M. A. Abdel Ghany, M. E. Bahgat,, W. M. Refaey and F. N. Hassan "Ant Colony Optimum Tuning of PID Load Frequency Controller for the Egyptian Power System", Accepted to be published in Sixteenth International Middle East Power Systems Conference (MEPCON'14), Ain Shams University, Egypt, 2014.

[19] H.A. Shayanfar H. Shayeghi, and A. Jalili, "Takagi-Sugeno Fuzzy Parallel Distribution Compensation Based Three-Area LFC Design" Journal on "Technical and Physical Problems of Engineering" (IJTPE), September Issue 8 Volume 3 No. 3 pp. 55-64, 2011.

[20] Mostafa H. E., "Artificial Intelligence-Based Load Frequency Control of MultiArea Power Systems", Ph.D. Thesis, faculty of engineering, Ain Shams university, Cairo, Egypt, 1999. 
[21] Mostafa H. E. ,"Load Frequency Control of the Egyptian Power System Using Bacterial Foraging Algorithm”, Portsaid Engineering Journal, Sept. 2012.

[22] Egyptian Electricity Holding Company, 2007/2008 Annual Report. http://www.egelec.com/annual\%20report/2007.htm.

[23] Yassin K., Abd-Raboh E. and Al-Domany M.S. Fast Power System Restoration Via Load Shedding Practices in Egyptian Power System", Mansoura Eng. Journal, Vol. 17, pp. 1-20, Mar Egypt, 1992.

[24] Qiao, W.Z and Mizumoto M, "PID type fuzzy controller and parameters adaptive method", Fuzzy Sets and Systems, Vol.78, pp 23-35. 1996.

[25] S. P. Ghoshal, Optimizations of PID gains by particle swarm optimizations in fuzzy based automatic generation control Electric Power Systems Research, Volume 72, Issue 3, pp 203-212, 15 December 2004.

\section{Nomenclatures:}

f Incremental frequency deviation $(\mathrm{Hz})$

Pd Load disturbance (p.u MW)

Pn1, Pn2, Pn3 Nominal rated regulating power output for non-reheat, reheat and hydro plants respectively (p.u MW)

P1， P2， P3 Incremental output power at the given loading condition of non-reheat, reheat, and hydro plants respectively (p.u MW)

R1, R2 Average governor droop setting of non-reheat and reheat plants respectively (Hz/p.u MW)

R3 permanent droop of the hydro plant speed governor (Hz/p.u MW)

$\mathrm{H} \quad$ Equivalent inertia const. of the system (sec.)

D Load dependency on frequency (p.u MW/Hz)

T1, T2 Steam valve time const. of non-reheat and reheat thermal plant respectively (sec.)

Th Time const. of reheat plant (sec.)

T3 Equivalent time const. of hydro plant (sec.)

$\mathrm{Tg} \quad$ Response time of speed governor (sec.)

Tw Water starting time in the hydro intake (sec.) 